\title{
ESCRITA FORA DA ESCOLA: experiências de crianças nos espaços de uma comunidade rural
}

\author{
Jacqueline Araujo Corrêa Mendes ${ }^{1}$ \\ Maria Lucia Castanheira ${ }^{2}$
}

\begin{abstract}
Resumo: A partir de subsídios dos Novos Estudos de Letramento, este artigo tem como objetivo investigar os usos e o envolvimento de crianças ${ }^{3}$, de uma comunidade rural do norte de Minas Gerais, com a escrita fora da escola. Neste contexto privilegiou-se a análise da participação de crianças dessa comunidade em eventos de letramento. Adotouse a pesquisa de perspectiva etnográfica e procedeu-se à observação participante no ano de 2012 na comunidade. O estudo envolveu a realização de entrevistas semiestruturadas, a produção de diário de campo, gravações de áudio e vídeo e coleta de artefatos escritos usados e/ou produzidos fora da escola. A pesquisa evidenciou que múltiplos letramentos ocorrem nesse contexto e que as crianças encontram disponibilidade e acesso à escrita na comunidade. Em contraposição, a pesquisa mostrou que, apesar do acesso e disponibilidade da escrita nos espaços da comunidade, esses saberes não fazem parte do acervo ensinado no contexto da escola local.
\end{abstract}

Palavras-chave: Escrita. Crianças. Comunidade rural. Disponibilidade. Acesso.

\section{WRITING OUT OF SCHOOL: Children's experiences in the spaces of a rural community}

Abstract: Based on the subsidies of the New Literacy Studies, this article aims to investigate the uses and the involvement of children, from a rural community in the north of Minas Gerais, with writing outside of school. In this context, the analysis of the participation of children from this community in literacy events was privileged. Research from an ethnographic perspective was adopted and a participant observation was carried out in 2012 in the community. The study involved conducting semi-structured interviews, the production a field diary, audio and video recordings and collecting of written artifacts used and/or produced outside the school. The research evinced that multiple literacies occur in this context and that children find availability and access to writing in the community. In contrast, the research showed that, despite the access and availability of

\footnotetext{
${ }^{1}$ Doutora em Educação. Professora regente na Universidade Estadual de Montes Claros e atua como membro da equipe multidisciplinar na Rede de Apoio à Inclusão de Pirapora. Minas Gerais, Brasil. E-mail: keline26@gmail.com. ORCID: https://orcid.org/0000-0002-1159-4356.

${ }^{2}$ Doutora em Educação. Professora do Programa de Pós-graduação em Educação da Universidade Federal de Minas Gerais (UFMG). Minas Gerais, Brasil. E-mail: lalucia@gmail.com ORCID: https://orcid.org/0000-0003-4839-9682.

${ }^{3}$ Um aspecto discutido com as crianças um mês após nossa inserção no campo de pesquisa diz respeito à preservação da identidade dos participantes conforme as normas do conselho de ética. Compreendida a determinação da resolução (n. 196/Conselho de Ética na pesquisa), no que diz respeito à preservação da identidade dos colaboradores na pesquisa, combinou-se que elas escolheriam um pseudônimo com o qual gostariam de ser nomeadas na pesquisa. Todos os colaboradores e a comunidade foram nomeados com pseudônimos.
} 
writing in the community spaces, these knowledges are not part of the patrimony taught in the context of the local school.

Keywords: Writing. Children. Rural Community. Availability. Access.

\section{ESCRITURA FUERA DE LA ESCUELA: Experiencias de niños en los espacios de una comunidad rural}

Resumen: Basado en los subsidios de los Nuevos Estudios de Literacidad, este artículo tiene como objetivo investigar los usos y el envolvimiento de los niños, de una comunidad rural en el norte de Minas Gerais, con la escritura fuera de la escuela. En este contexto, se privilegió el análisis de la participación de los niños de esta comunidad en eventos de literacidad. Se adoptó la investigación desde una perspectiva etnográfica y se realizó observación participante en 2012 en la comunidad. El estudio implicó la realización de entrevistas semiestructuradas, la producción de un diario de campo, grabaciones de audio y video y la recolección de artefactos escritos utilizados y/o producidos fuera de la escuela. La investigación mostró que se producen múltiples literacidades en este contexto y que los niños encuentran disponibilidad y acceso a la escritura en la comunidad. En contraste, la investigación mostró que, a pesar del acceso y disponibilidad de escritura en espacios comunitarios, estes conocimientos no hacen parte de la colección enseñada en el contexto de la escuela local.

Palabras clave: Escritura. Niños. Comunidad rural. Disponibilidad. Acceso

\section{Introdução}

Neste trabalho, analisamos as maneiras pelas quais a escrita se faz presente na vida cotidiana de crianças numa comunidade rural no norte de Minas, especialmente, em situações sociais ocorridas fora da escola. Nesta análise, exploramos ideias e conceitos da abordagem dos Novos Estudos do Letramento (NEL), termo recentemente definido por Street (2014) em Letramento como Prática Social (LPS). Além de trabalhos vinculados a essa abordagem, exploraremos o conceito de fundos de conhecimento proposto por Moll (1992), que adota uma perspectiva sociocultural no estudo das práticas culturais de imigrantes que vivem nos Estados Unidos. Nesta perspectiva, a questão que motivou esse estudo é com qual escrita as crianças se envolvem na comunidade? Qual escrita é valorizada na comunidade?

De acordo com Barton e Hamilton (1998), o letramento existe na vida cotidiana das pessoas quando elas fazem uso da leitura e da escrita em atividades diversas em casa, no local de trabalho e na escola, sendo, portanto, um recurso cultural utilizado em relações sociais e não uma propriedade dos indivíduos. Street (2014, p.147) nos lembra que para "descrever a especificidade dos letramentos em lugares e tempos particulares" convém utilizar o conceito de "eventos de letramento". Eventos de letramento, de acordo com 
Heath (1983), pode ser entendido como "qualquer situação em que a escrita é fundamental à natureza das interações dos participantes e a seus processos interpretativos" (HEATH, $1983^{4}$ citado por STREET, 2014, p. 147). Pareceu-nos útil na busca de identificação dos eventos de letramento na comunidade rural considerar os conceitos de disponibilidade da escrita e o acesso à escrita proposto por Kalman (2004). Para Kalman, disponibilidade da escrita refere-se a presença física dos materiais impressos e a infraestrutura onde essa escrita circula, e acesso à escrita refere-se as oportunidades que as pessoas têm de interagir com a língua escrita em eventos de letramento. Como descrito por Kalman (2004, p. 26),

Disponibilidad denota la presencia física de los materiales impresos y la infraestructura para su distribuición (biblioteca, puntos de venta de libros, revistas, diarios, servicios de correo, etcétera), mientras que accesso se refiere a las oportunidades para participar en eventos de lengua escrita, situaciones en las cuales el sujeto se posiciona vis-à-vis com otros lectores y escritores, así como a las oportunidades y las modalidades para aprender a leer y escribir.

Nos procedimentos metodológicos de sua pesquisa, na comunidade de Mixquic,

no México, Judith Kalman iniciou seu trabalho fazendo um levantamento da escrita disponível naquela cultura. Foi a partir desse levantamento que a autora cunhou o conceito de "disponibilidade" como todos os materiais e lugares em que a escrita aparece.

Quanto a disponibilidade, Kalmam (2004) verificou que artefatos escritos estavam presentes em vários espaços da comunidade de Mixquic (México). Nas casas, na igreja, na escola, no correio, na biblioteca e em outros. Esses lugares ofereciam também múltiplas situações para ler e escrever. Segundo Kalman (2004) as situações de acesso que envolviam a leitura e escrita nesses espaços podiam ocorrer de três formas: em situações demandantes, situações de andaime ou situações voluntárias.

Exemplificando essas três formas, Kalmam (2004) mostra que uma situação demandante ocorre, por exemplo, quando um cliente recorre ao atelier de costura cobrando um serviço. A costureira solicita que ele assine o recibo, confirmando a entrega do serviço. Dessa maneira, o cliente fez uso da escrita a partir de uma demanda, ou seja, receber a mercadoria encomendada. Outras situações que exigem conhecimento da leitura

\footnotetext{
${ }^{4}$ HEATH, Shirley Brice. Ways with words: language, life, and work in communities and classrooms. New York: Cambridge University Press, 1983.
} 
e da escrita para participar delas são, por exemplo, o voto secreto nas eleições, assinar documentos legais e outros, caracterizando-se como "situações demandantes".

Uma situação de andaime ocorre quando uma pessoa ajuda outra na realização de uma tarefa que exija a leitura ou escrita. como os pais ajudando seus filhos na tarefa escolar ou quando uma pessoa ajuda outra em uma transação financeira junto ao banco.

Já a situação voluntária ocorre, por exemplo, quando uma pessoa parada diante de uma banca de revista lê as capas e escolhe qual delas irá comprar. Muitos outros exemplos poderiam exemplificar esses três tipos de situações: quando se lê as manchetes de um jornal buscando as notícias que deseja, quando uma pessoa para diante de um cartaz e o lê, quando se escreve um ofício, carta ou um e-mail e muitas outras. Essas situações podem também acontecer em lugares distintos ou coincidir em um mesmo espaço. Ou seja, as três situações podem ocorrer quando, por exemplo, uma bibliotecária explica ao usuário como usar o sistema de classificação - é uma situação de andaime; quando o usuário consulta as estantes - é uma situação demandante; quando o leitor toma um livro nas mãos e o olha porque lhe interessou - é uma situação voluntária (KALMAM, 2003; 2004).

Essas diferentes situações se dão com propósitos variados na relação social e implicam conhecimentos e ações específicas de leitura e escrita entre os participantes em um evento de língua escrita e também na relação deles com a cultura escrita. É esse conjunto de relações, conhecimentos e ações que constituem o acesso e as modalidades de apropriação.

Desse modo, se é por meio das relações sociais que se constrói o acesso à cultura escrita, acreditamos que para compreender os significados atribuídos à escrita pelos participantes da pesquisa seja necessário examinar como a escrita se torna disponível para os moradores da comunidade pesquisada e como as crianças têm a possibilidade de acesso aos seus usos.

Como mencionado acima, outro conceito relevante para a análise desenvolvida neste trabalho é o conceito de fundos de conhecimento (MOLL, 1992). Moll define fundos de conhecimento como o agregado familiar de recursos historicamente acumulados e culturalmente desenvolvidos de conhecimentos, habilidades e competências essenciais para desenvolver atividades cotidianas e para o bem-estar das pessoas. O conceito de fundos de conhecimento é relevante neste estudo, pois, ao indicar a necessidade de ter um 
olhar etnográfico para os recursos historicamente acumulados e culturalmente desenvolvidos de saberes, habilidades e competências peculiares para desenvolver atividades cotidianas presentes nas famílias das crianças que participam dessa pesquisa buscamos conhecer aspectos das experiências das crianças com a escrita fora da escola, que até o momento desconhecemos.

Para Moll (1992), a escola subestima o que as crianças de meios menos privilegiados são capazes de exibir intelectualmente. O autor afirma que a aplicação de recursos culturais desse grupo no ensino poderia favorecer no desempenho dessas crianças. Segundo Moll, uma maneira de compreender esse conceito é a partir de outros fundos que fazem parte do cotidiano das famílias, termo utilizado por Greenberg ${ }^{5}$ (1989 apud MOLL, 1992, p. 217).

Os mais básicos são os fundos calóricos, que são necessários para sustentar a vida. Mas há outros fundos domésticos importantes, tais como: fundos de aluguel, uma taxa sobre a produção das famílias, resultantes de uma reivindicação superior no terreno ou habitação; fundos de substituição, que representam o montante necessário para substituir ou manter equipamentos mínimos de produção e consumo; e fundos de cerimonial, que sustentam os aspectos simbólicos das relações sociais, como cerimônias de casamento e outros rituais encontrados na escala social $[\ldots]^{6}$. (Tradução nossa).

Esses e outros fundos formam um conjunto mais amplo de atividades que exigem conhecimentos específicos de importância estratégica para as famílias. É esse repertório que Moll denomina "fundos de conhecimento". O grupo de pesquisa de Moll (1992) produziu uma série de dados sobre os "fundos de conhecimento" das famílias como: composição do agregado familiar, rotinas diárias, a participação das crianças em atividades domésticas, as práticas de leitura dos pais em línguas espanhola e inglesa e avaliações de leitura e escrita. Esses dados indicaram aos pesquisadores a relação de conhecimentos que poderiam ser incorporados aos saberes escolares, oferecendo subsídios para o trabalho dos professores.

\footnotetext{
${ }^{5}$ Greenberg, J. B. (1989). Funds of knowledge: Historical constitution, social distribution, and transmission. Paper presented at the Society for Applied Anthropology, Annual Meeting, Santa Fe.

${ }^{6}$ The most basic are caloric funds, which are needed to sustain life. But there are other importante household funds, such as: funds of rent, a charge on the households'production resulting from a superior claim on the land or housing; replacement funds, which represent the amount needed to replace or maintain minimum equipment for production and consumption; and ceremonial funds, which sustain symbolic aspects of social relationschips, such as marriage ceremonies and other rituals found in the social order [...] (MOLL, 1992, p. 217)
} 
Ao explorar o conceito de fundos de conhecimento e de eventos de letramento, foi possível identificar várias situações ocorridas fora da escola em que as crianças estiveram envolvidas com a escrita em casa, nas ruas, em ambientes comerciais ou em serviços públicos. Subsidiada pelos conceitos de práticas e eventos de letramento (HEATH, 1983; STREET, 1984), disponibilidade e acesso à escrita (KALMAN, 2004), além de fundos de conhecimento (MOLL, 1992), examinamos a seguir quando e como a escrita se faz presente em alguns espaços sociais da comunidade, ou seja, observamos onde, quando e como os participantes da pesquisa fazem uso da escrita. Essa análise é feita a partir de relatos dos moradores entrevistados, gravações de áudio e vídeo, análise de artefatos e notas de campo. O trabalho de campo propiciou recolher uma série eventos de letramento, no entanto, padrões foram surgindo durante as observações evidenciando os usos sociais da escrita. Isso possibilitou uma seleção dos eventos para a análise. Neste artigo descrevemos alguns desses eventos.

Desse modo, iniciamos com a descrição da disponibilidade da escrita em três espaços sociais da comunidade. Identificar a presença da escrita na comunidade não foi uma tarefa difícil. Por outro lado, o acesso demandou um olhar mais atento na busca de compreender como as pessoas fazem usos sociais da escrita nesse contexto.

$\mathrm{Na}$ comunidade a escrita estava disponível em muitos lugares e se apresentava com certa diversidade em: placas que identificavam obras e nomes de ruas; cartazes que informavam sobre eventos na comunidade e fora dela; cadernos de anotações para os serviços de telefone, saúde e compras na mercearia do Sr. Joaquim; bilhetes que levavam e traziam recados entre os moradores; atas que testemunhavam as ações da Associação ou da Rede Coopcerrado; textos religiosos para o trabalho de evangelização e muitos outros poderiam ser listados aqui. Para representar os padrões que ocorreram nesse contexto apresentamos três eventos: no primeiro a disponibilidade e o acesso da escrita no posto de saúde, no segundo, a escrita no posto telefônico e, no terceiro, no comércio.

\section{Escrita relacionada à saúde: no posto de saúde}

O posto de saúde ocupava três salas cedidas pela Associação dos Pequenos Produtores Rurais da comunidade. Estava localizado bem próximo da casa alugada pelas pesquisadoras na comunidade. Nas paredes da sala principal do posto de saúde, cartazes informativos sobre doenças e cuidados com a saúde estavam disponíveis aos moradores (crianças e adultos) que frequentassem esse local (FIG. 1). 


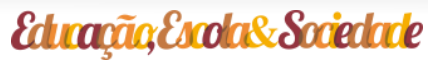

FIGURA 1: Cartazes de prevenção afixados na parede do Posto de Saúde

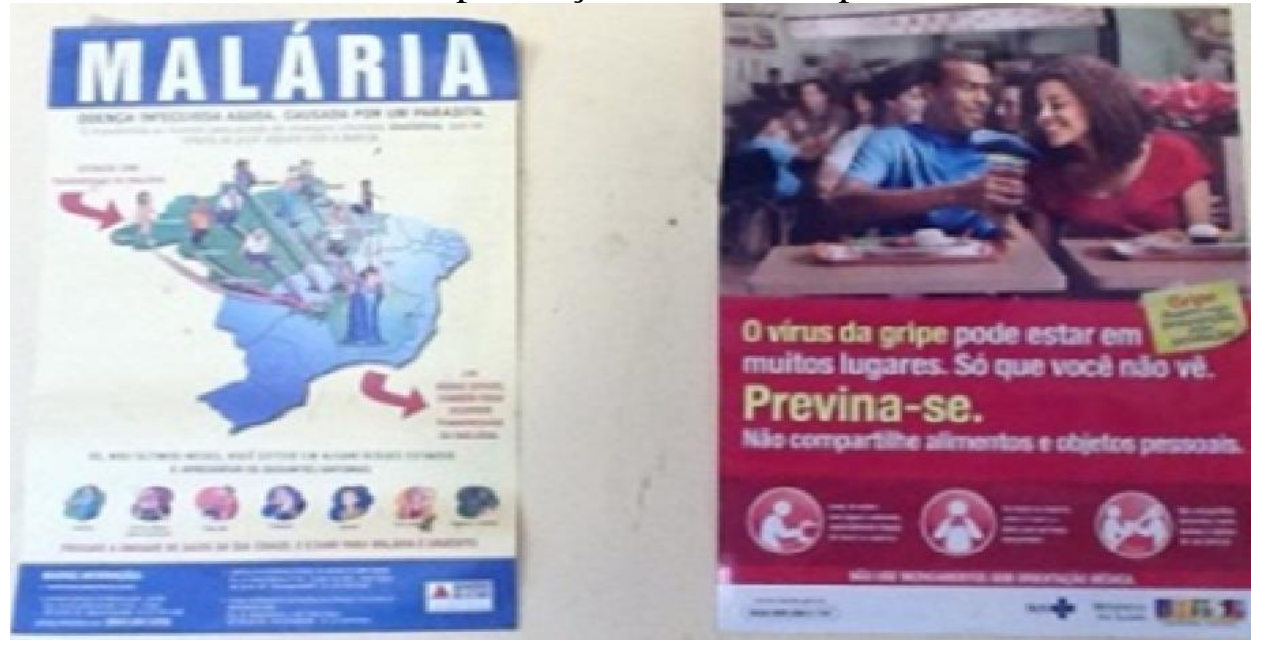

Fonte: Trabalho de campo, 2012.

Algumas vezes foi possível observar moradores entretidos com as imagens e a escrita dos cartazes no posto de saúde. Entretanto, não presenciamos nenhuma discussão em torno deles. As informações mais evidentes dessa interação, sobretudo do cartaz (FIG. 1) que informa sobre "Malária", vieram da agente de saúde e de relatos de moradores a respeito das pessoas com a doença de chagas na comunidade. Segundo a agente de saúde, toda vez que algum morador encontrava um barbeiro em casa colocava-o em frascos de vidro e, assim, eram entregues a ela, que os enviava à instituição de saúde responsável na cidade. Essa instituição era encarregada de providenciar o exame do barbeiro e, após os resultados, deveria informar à comunidade se o barbeiro estava contaminado ou não. De acordo com a agente de saúde, vários barbeiros já foram enviados para análise, mas o retorno demorava ou mesmo nunca chegava. O cartaz sobre "Malária" (FIG. 1) era bastante ilustrativo e seu conteúdo funcional e estético informava as pessoas que, nos estados da região norte, centro-oeste e, principalmente, em Minas Gerais, pode ocorrer a transmissão da Malária. Ele avisava que, se a pessoa, nos últimos meses, apresentasse algum dos sintomas listados e ilustrados no cartaz, deveria procurar a unidade de saúde de sua cidade para fazer o exame médico. Tanto os cartazes do posto de saúde quanto cartazes de aniversários e placas expostas na comunidade fazem parte da vida social e são de conhecimento dos moradores. E, por vezes, eram as placas de investimentos públicos que geravam maiores discussões entre os moradores. No período deste trabalho de campo, presenciamos também as interações dos moradores com os materiais produzidos por candidatos às eleições municipais: cartazes, folders, "santinhos" e outros. 
Informações escritas sobre a saúde também eram repassadas oralmente aos moradores pela agente responsável. Lúcia era a agente de saúde contratada pela prefeitura e que atendia os moradores da comunidade há sete anos. Com formação em auxiliar técnica de enfermagem, estava sempre pronta a atender os moradores, mesmo fora de seu horário de trabalho. $\mathrm{O}$ atendimento com o médico acontecia de 15 em 15 dias, às segundas-feiras, quando o clínico geral se deslocava da cidade até a comunidade. Nos dias de atendimento, Lúcia acompanhava o médico nas consultas. Organizava as fichas, pesava e media os pacientes, dava informações de seu atendimento domiciliar e entregava medicamentos. O acompanhamento do desenvolvimento das crianças era também contínuo. Segundo Lúcia nenhuma criança da comunidade estava com sintomas de desnutrição. As orientações aos pais sobre os cuidados com a alimentação e o programa da Pastoral de distribuição do leite na comunidade vinham contribuindo para reverter o quadro de desnutrição infantil. Além disso, Lúcia fazia visitas domiciliares para acompanhar a situação de saúde e de tratamento dos moradores da comunidade e das fazendas próximas. Para o acompanhamento e controle das doenças, ela mantinha um caderno de anotações e outras fichas atualizadas. Uma ficha do Programa de Saúde da Família (PSF) registrava a visita, e ao paciente era solicitado que assinasse na ficha atestando a visita (FIG. 2). Outra ficha, que ficava na casa do paciente, informava a data da próxima visita. Temos aqui uma "situação demandante" de escrita como evidenciado nas pesquisas de Kalmam (2004). Isto é, a confirmação por meio de assinatura do morador que recebeu o serviço prestado pela agente de saúde e o registro da agente de saúde na ficha do morador informando a data da próxima visita.

FIGURA 2: Ficha de acompanhamento da saúde das famílias

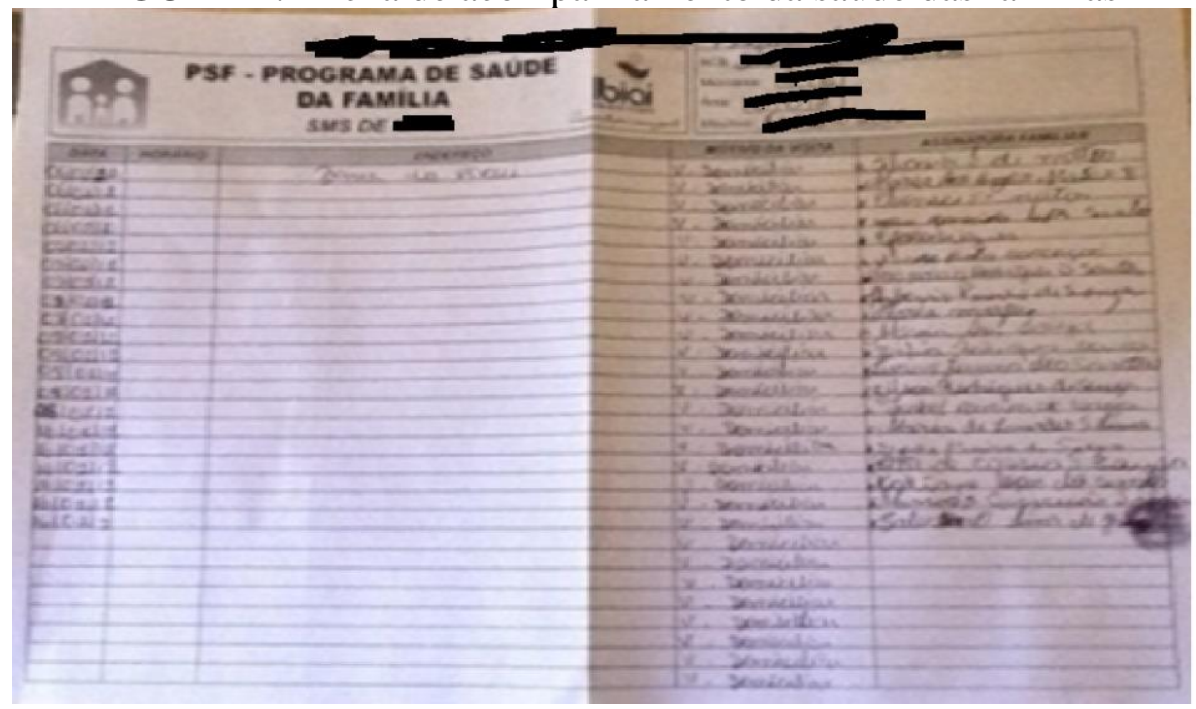

Fonte: Trabalho de campo, 2012. 
Alguns programas como a distribuição de leite para as crianças da comunidade, o acompanhamento de gestantes, diabéticos e hipertensos e o controle de doenças como Leishmaniose e Chagas requeriam maior atenção. Segundo Lúcia, na comunidade atualmente havia 35 pessoas hipertensas e 5 diabéticos. Lúcia também tinha os dados individuais de cada morador da comunidade como nome completo e data de nascimento.

Na página do caderno de anotações abaixo, no registro (FIG. 3), feito no ano anterior, constam os seguintes dados: 60 famílias morando dentro da comunidade e 35 nas fazendas. Hipertensos 44, diabéticos 9, fumantes 20, doença de chagas 33 e distúrbios mentais 6. Duas abreviações são utilizadas nas anotações de Lúcia para se referir a dados diferentes a letra "M" (maiúscula) para mulheres e para mês. Quando ela específica em suas anotações o número de idosos acima de 60 anos o faz "H 12" e "M 11", da mesma forma específica quantos sofreram quedas nos últimos "6 M" para se referir a meses, ou seja, aqueles idosos que perderam o equilíbrio e caíram nos últimos seis meses. A diferenciação no emprego dos termos em ambas as situações se dá pela posição da letra antes e após o número. Percebemos nos registros que letras são utilizadas como forma de classificação e diferenciação de pacientes, e os números informam o universo de seu atendimento e quais requerem maior atenção. Que nesse caso seriam idosos que tomam mais de 5 tipos de remédio e apresentam mais de 5 tipos de doenças. Observa-se que nos registros de Lúcia estão presentes tanto os saberes escolares quanto fundos de conhecimento (MOLL, 1992) internalizados ao longo de sua experiência com a função de técnica de enfermagem.

FIGURA 3: Caderno de anotações da agente de saúde.

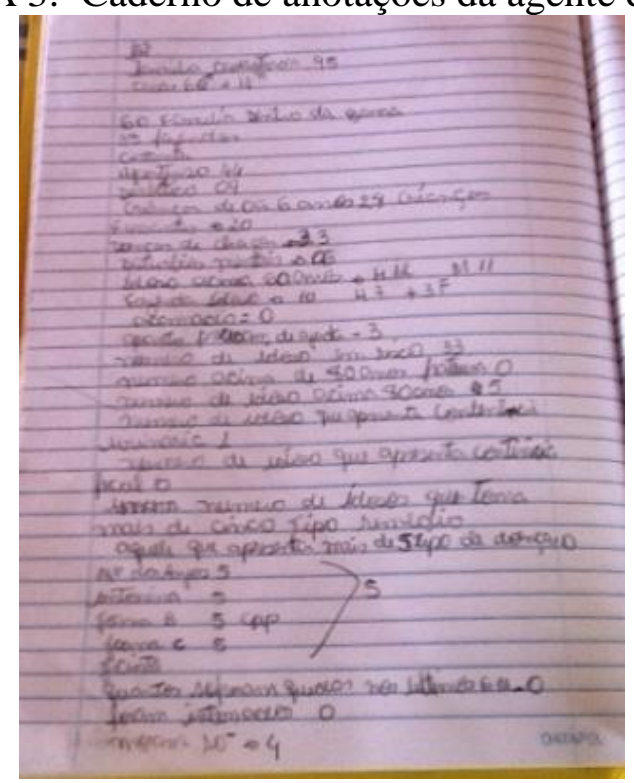

Fonte: Trabalho de campo, 2012. 
Durante a visita domiciliar ela monitorava a pressão dos pacientes anotando o resultado em seu caderno, orientava sobre medicamentos (dosagem e efeitos colaterais) e sobre os cuidados com a alimentação. O controle da diabete não era possível com a verificação da glicemia, isto porque no posto não havia aparelho para esse controle. No entanto, Lúcia orientava os pacientes quanto aos cuidados necessários. Ela também informava aos moradores sobre as campanhas de vacinação. Dessa forma, a interação com a escrita se dava pelo registro de dados nas fichas dos pacientes e no caderno de Lúcia, além das informações sobre a saúde, repassadas oralmente.

As atividades desenvolvidas por Lúcia favoreciam o acesso dos moradores ao serviço de saúde. A escrita muito própria da área de saúde como: receitas médicas, bulas de medicamentos, muitas com terminologias complicadas, podiam ser esclarecidas por Lúcia. Além do médico, ela era a pessoa com autoridade na comunidade para prestar esclarecimentos de sua área. Os registros feitos por Lúcia em seu caderno de anotações podem ser percebidos também como um fichário que guarda informações relevantes sobre a saúde dos moradores. Eles têm conhecimento disso e podiam recorrer a ela quando precisavam utilizar essas informações. Quando fizemos o levantamento da quantidade de pessoas que moravam na comunidade, foi por intermédio de Lúcia que conseguimos os dados atualizados. Aqui também encontramos uma "situação de andaime" da leitura e escrita anunciada nos escritos de Kalmam (2004).

No primeiro semestre de 2012 presenciamos um dia de interação dos alunos da escola com o posto de saúde. $\mathrm{O}$ atendimento às crianças aconteceu no dia 04 de junho. Às 10 horas e 45 minutos, Patrícia, a auxiliar do posto telefônico, e a coordenadora da escola, Alana, chegaram à porta da sala de aula e avisaram aos alunos que o médico os aguardava para exame. Esta solicitação era feita todos os anos para que os alunos pudessem ser liberados ou não para fazer a educação física. Naquele dia, o médico atendeu 14 crianças da escola. A coordenadora da escola acompanhou as crianças até o posto (FIG.4). Ao entrar no posto, algumas crianças se sentaram nas cadeiras disponíveis e outras ficaram em pé. Lúcia foi chamando uma por uma. Pegou as fichas médicas das crianças, que estavam em envelopes em cima da mesa no ambulatório, depois pesou e mediu cada uma registrando os dados na ficha. À medida que pesava e media os alunos, Lúcia os informava do peso e medida. Esses dados eram motivo de comparação entre as crianças, que, a todo o momento, queriam saber o resultado dos colegas. 
FIGURA 4: Alunos fazem avaliação no posto de saúde.

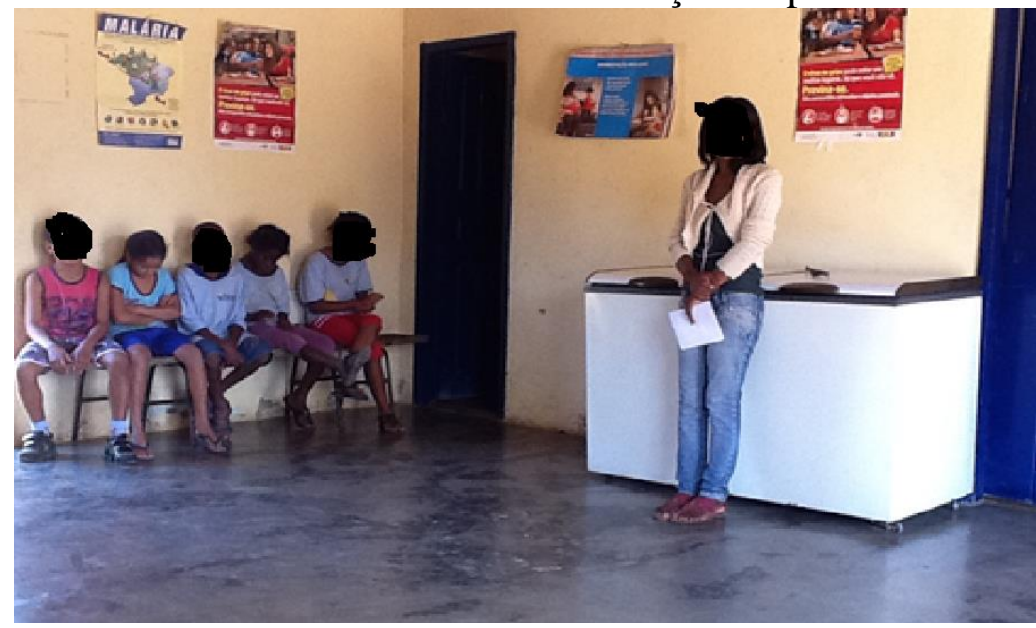

Fonte: Trabalho de campo, 2012.

Após medir e pesar as crianças e informá-las sobre isso, Lúcia entregava as fichas individuais ao médico, que passava a chamar as crianças que aguardavam na sala principal. Durante a espera na sala principal, observamos Júlia, aluna do $5^{\circ}$ ano, dizer à coordenadora que se o médico perguntasse alguma coisa, ela iria mentir, porque não gostaria de ficar sem fazer educação física. A coordenadora avisou que isso não adiantaria, porque o médico perceberia ao examiná-la. Quando chegou a vez de Júlia, a consulta foi mais demorada. Sua mãe teve que ser chamada ao consultório e o médico

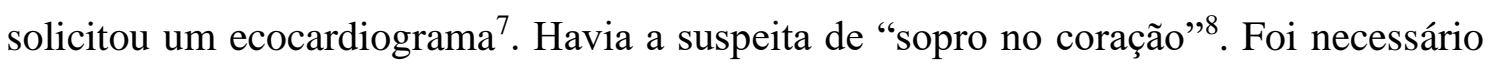
esclarecer o problema para que as pessoas responsáveis por Júlia compreendessem o que era o diagnóstico inicial e a importância de fazer o exame. O médico deu os esclarecimentos necessários à mãe e à coordenadora Alana. O médico também recomendou que Júlia não fizesse educação física até ter o resultado do exame. Júlia saiu muito chateada do consultório e, naquele dia, a notícia se espalhou. Todos os alunos comentavam o problema de Júlia. Ela também passou a ser vigiada pelos colegas e, quando fazia algum esforço físico, era logo denunciada para a professora e para a coordenadora.

\footnotetext{
${ }^{7}$ Para fazer o ecocardiograma o paciente fica deitado de barriga para cima, inclinado sobre o lado esquerdo. É aplicado um gel no tórax para facilitar a condutividade das ondas sonoras. O técnico coloca sobre o peito do paciente um pequeno dispositivo semelhante a um microfone, denominado transdutor, que será responsável por captar o retorno dos sons e ajudar a formar as imagens do músculo cardíaco.

${ }^{8}$ Sopro cardíaco é um ruído produzido pela passagem do fluxo de sangue através das estruturas do coração. Ele pode ser funcional ou fisiológico (sopro inocente), ou patológico em decorrência de defeitos no coração. Cerca de 50\% das crianças saudáveis apresentam sopros inocentes sem nenhuma outra alteração e com desenvolvimento físico normal. Disponível em: http://drauziovarella.com.br/crianca-2/sopro-no-coracao/ Acesso em 13/10/2014.
} 
Com o pedido do exame médico, a mãe de Júlia recebeu orientação da agente de saúde para procurar a Secretaria Municipal de Saúde da cidade para marcar o ecocardiograma. Foi necessário aguardar mais de dois meses para que o exame fosse feito pelo Sistema Único de Saúde (SUS). Após os resultados, que indicaram uma alteração sem maiores consequências, Júlia pode retomar a sua vida normal e, como qualquer criança da comunidade, que adorava jogar futebol, não perdeu tempo.

Até aqui percebemos que no posto de saúde a escrita estava disponibilizada em cartazes nas paredes, nas fichas de acompanhamento da saúde, no caderno de Lúcia e eram repassadas oralmente por ela aos moradores. Os moradores da comunidade tinham acesso aos serviços de saúde através dos programas de acompanhamento no posto e do atendimento domiciliar. Estes eram realizados por meio da interação com a agente de saúde e, na maioria das vezes, requeriam o registro escrito do atendimento. Informações sobre doenças também eram esclarecidas com o médico que buscava deixar o conhecimento acessível à compreensão dos interessados. Isto evidencia a existência de espaços onde a escrita permeia as atividades diárias das pessoas da comunidade, ou seja, a disponibilidade da escrita em materiais como cartazes, fichas e receitas médicas e o acesso permite que as pessoas e principalmente as crianças participem da leitura e escrita conforme suas necessidades reais (BARTON e HAMILTON, 1998; KALMAN, 2003).

A respeito do problema de saúde que envolveu Júlia e sua família, "sopro no coração", sintoma até então desconhecido para muitos na comunidade, a situação trouxe novos significados a respeito do problema. Houve a compreensão de que não se tratava de uma doença, mas que era necessário observar as ações de Júlia, se o esforço físico indicava cansaço em excesso ou se manifestava outros comportamentos que mostrassem algum problema mais grave. O ecocardiograma foi o exame que trouxe a confirmação do estado de saúde de Júlia. O exame também a envolveu, com sua mãe, em novas leituras. Por meio do exame Júlia e sua mãe visualizaram o coração em uma tela enquanto o técnico/médico explicava as condições de saúde de Júlia. Elas tomaram conhecimento de informações próprias do domínio discursivo da saúde. Outro momento foi o retorno ao médico da comunidade. Ele avaliou o exame, esclareceu o problema e deu orientações para o dia a dia de Júlia.

A escrita nesse contexto estava associada a um campo de conhecimento, a uma autoridade que definia as condições de participação das crianças em uma atividade escolar - a educação física. Essa autoridade era reconhecida na comunidade o que é observado 
na atitude dos colegas de Júlia, que passaram a vigiar seu comportamento ante a proibição do médico.

O acesso por meio da escrita produziu também comentários entre as crianças diante do registro das medidas tamanho e peso: quem era maior ou menor, quem pesava mais ou menos. Nesse evento de letramento envolvendo o numeramento, percebemos como as ações das crianças estavam situadas em uma atividade social de um campo específico, a área da saúde, e que nesse contexto associava-se a usos reais (KALMAN, 2004).

Observamos que no Posto de Saúde da comunidade o serviço público de saúde oferecia disponibilidade e acesso à escrita pela exposição de cartazes nas paredes, em fichas próprias da instituição e pela comunicação oral feita pela agente de saúde. O acesso à escrita envolvia os moradores em "situações demandantes" e "situações de andaime" (KALMAM, 2004). A seguir analisa-se eventos e práticas de letramento envolvendo o posto telefônico.

\section{Escrita no posto telefônico}

Outra instituição na comunidade em que a interação dos moradores com a escrita se dava era o posto telefônico. Ele também estava localizado na Associação dos Pequenos Produtores Rurais da comunidade. O telefone do posto pertencia à Associação e estava conectado ao mundo fora da comunidade por uma antena a rádio. Patrícia, mãe de Neimar, colaborador desta pesquisa, era a responsável pelo posto telefônico e estava sempre pronta para atender os usuários. Patrícia tinha 36 anos, estudou até a $5^{\text {a }}$ série do ensino fundamental e trabalhava no posto telefônico há dois anos. Sua contratação foi feita pela gestão municipal em resposta à demanda dos membros da Associação dos Pequenos Produtores Rurais de que houvesse uma pessoa para intermediar o serviço de telefonia na comunidade.

Patrícia foi contratada como auxiliar de serviços públicos. Ela morava com sua mãe e os três filhos, bem próximo ao posto telefônico. Ao assumir o cargo, Patrícia procurou maneiras de organizar o atendimento no posto. Para isso, buscou junto à empresa de telefonia informações sobre os preços das ligações. A empresa lhe forneceu uma tabela com o preço das ligações por minutos. Com esses dados em mãos, Patrícia organizou um caderno para o registro dos atendimentos. Quando um morador usava o 
telefone, ela marcava os minutos no seu celular e o custo da ligação era feito com base na tabela da empresa de telefonia (FIG. 4).

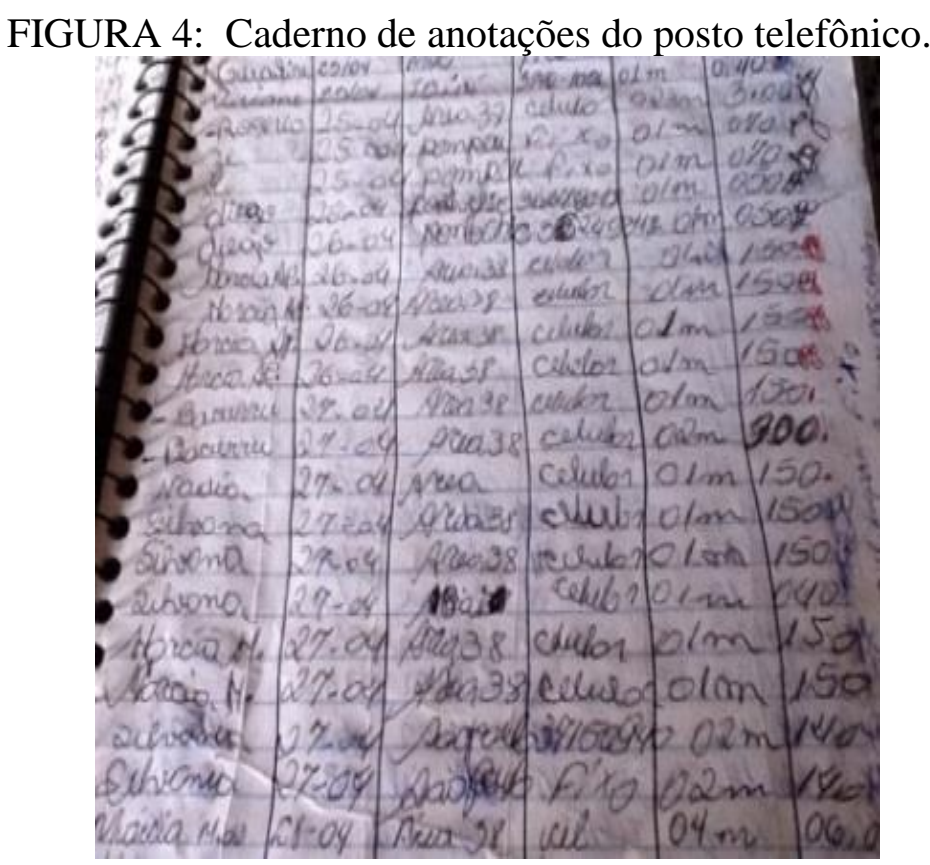

Fonte: Trabalho de campo, 2012.

Assim, como a agente de saúde, Patrícia utilizava uma tabela para registrar e organizar os atendimentos no posto. A tabela era composta das seguintes colunas: nome, data, área/cidade, ou seja, Discagem Direta a Distância (DDD), tipo (se para celular ou telefone fixo), minutos e total. Existia um valor que era cobrando além dos minutos utilizados pelos usuários que correspondia a "assinatura" da linha telefônica. As despesas com essa assinatura eram acrescentadas as ligações daqueles que utilizassem o serviço, e todos concordavam com essa norma. $\mathrm{O}$ total da ligação era informado após a cada registro e alguns usuários costumavam pagar quando usavam o serviço, outros não. Quando a conta de telefone chegava, Patrícia precisava cobrar dos devedores o montante correspondente à ligação feita por cada um deles.

Parei no posto telefônico e conversei com Patrícia. No momento da conversa uma moradora da comunidade chegou para fazer uma ligação interurbana. Patrícia pegou o telefone e discou o número ditado pela moradora. Aguardou que a ligação se completasse e passou o telefone para a moradora. Assim que a moradora começou a conversar Patrícia começou a marcar os minutos no seu celular. Registrou alguns dados da usuária no caderno de controle e se retirou da sala para que a moradora tivesse maior privacidade. Quando a moradora terminou Patrícia marcou o tempo da ligação e lhe passou o valor. A moradora 
pediu para pagar no dia que recebesse a aposentadoria. Patrícia concordou. (Notas. Diário de campo, 2012).

Algumas vezes era o irmão mais velho de Neimar que tomava conta do posto telefônico. Isto ocorreu sempre que Patrícia, sua mãe, precisou resolver alguma coisa na cidade. Da mesma forma como Patrícia atendia aos usuários, seu filho também o fazia. Discava o número solicitado, aguardava o sinal e passava o telefone ao usuário. Em seguida controlava os minutos no celular e ao final da ligação calculava o valor total da ligação informando ao usuário. Percebe-se aqui uma flexibilidade de papéis, isto é, a atribuição a um adolescente que podia fazer o papel da assistente contratada e o reconhecimento dos moradores de que ele detinha saberes necessários para o fazer. Essa situação revela também a presença de fundos de conhecimento descritas por Moll (1992).

O caderno de registro das ligações telefônicas ficava em cima do balcão do posto e estava sempre à disposição de qualquer usuário que porventura quisesse conferir seus débitos ou mesmo identificar números de telefones de que necessitasse (como se estivesse conferindo uma agenda telefônica). Dessa forma, a interação com a escrita, nesse caso, tinha a finalidade de resolver assuntos pessoais ou familiares intermediados pelo serviço de telefonia. Como nas fichas de visita do Posto de Saúde, no caderno de registro das ligações a coluna destinada ao nome, podia ser preenchida pelo usuário ou pela assistente do posto. Essa assinatura também confirmava o serviço prestado e o valor do serviço. Isto é, o uso da escrita em uma "situação demandante" (KALMAM, 2004). As práticas de leitura e escrita no posto telefônico tinham um caráter comercial e, também, realizavamse em contextos de uso real (KALMAN, 2004). Prosseguindo verifica-se práticas e eventos de letramento no comércio.

\section{Escrita no comércio}

Outros lugares também muito frequentados na comunidade eram três pontos comerciais, sendo eles duas casas bar e uma mercearia. Em frente à Associação dos Pequenos Produtores Rurais da comunidade, funcionava a casa mercearia. Produtos diversos eram encontrados na mercearia: alimentos não perecíveis, linguiça e frango congelado, produtos de limpeza, lápis, caneta, caderno e outros. A disponibilidade da escrita na mercearia do Sr. Joaquim estava nos rótulos dos produtos nas estantes, nos cartazes de propaganda de produtos como cerveja e nos de prevenção como o do Conselho Tutelar - além do alvará de funcionamento da prefeitura, que informava a legalidade do 


\section{Edurañâ,Escolar Sociedace}

estabelecimento comercial - pregados nas paredes. Quando um morador precisava de algum mantimento, era possível comprar na mercearia e anotar no "caderno de fiado" do Sr. Joaquim (FIG. 5). O produto comprado a prazo na mercearia do Sr. Joaquim era pago mensalmente. Esses compradores, em geral, recebiam os recursos do programa Bolsa Família ou eram aposentados como trabalhadores rurais.

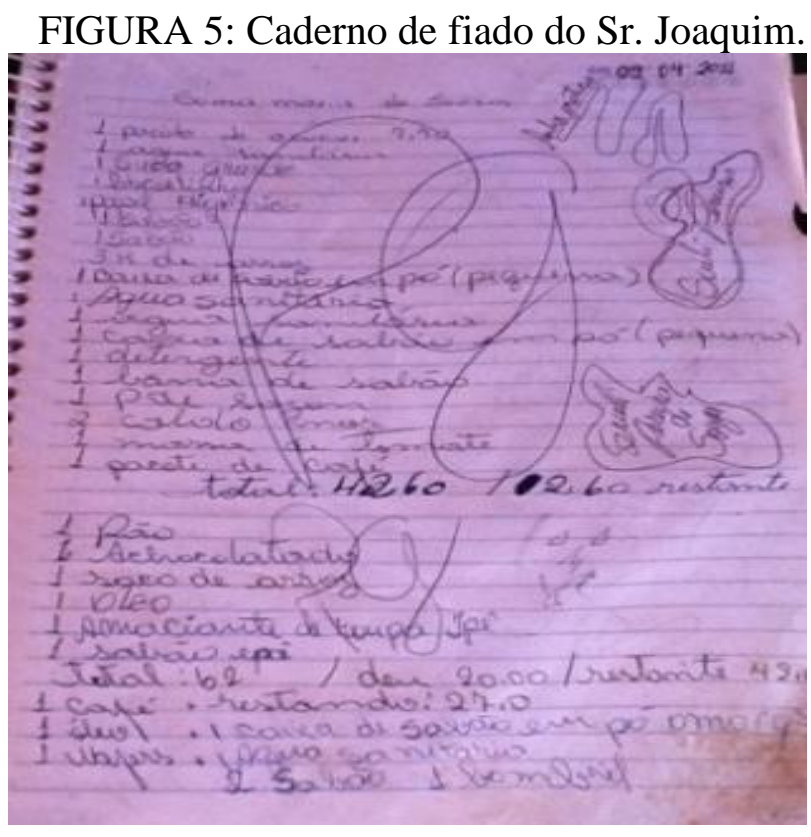

Fonte: Trabalho de campo, 2012.

No caderno de fiado (FIG. 5), Sr. Joaquim listava a quantidade e o nome do produto comprado. $\mathrm{O}$ valor era cobrado no dia em que o devedor quitava sua dívida. Isto porque o valor do produto podia sofrer alteração de acordo com a inflação. Esse controle sobre o valor da mercadoria era feito sempre que o Sr. Joaquim recebia nova carga dos produtos.

Percebemos em conversa com o Sr. Joaquim que as crianças interagem com a escrita em eventos de letramento nesse contexto. Segundo o senhor Joaquim, quando seus clientes enviavam os filhos menores para comprar algum produto a ser anotado no caderno de débitos, precisavam enviar um bilhete assinado pelo responsável. Esses bilhetes eram guardados no caderno até que os pais pagassem os seus débitos. O Sr. Joaquim afirmou que, quando as crianças chegavam à mercearia, diziam o conteúdo escrito no bilhete mesmo antes que ele lesse. A afirmação do Sr. Joaquim de que as crianças já chegavam anunciando o que estava escrito no papel evidencia que os pais tinham a preocupação de mostrar a elas o que deveria ser anotado pelo Sr. Joaquim no "caderno de fiado" e limitar as compras a serem feitas. 
O bilhete nessa situação cumpria uma função social, isto é, por meio de um escrito sucinto os pais atendiam à exigência do comerciante, que tinha como critério mais importante a especificação do nome do produto, a quantidade e a responsabilização do comprador por meio da assinatura. Essa exigência do Sr. Joaquim se devia à sua desconfiança em relação à atitude de algumas crianças da comunidade, conforme ele disse em uma de nossas conversas:

Sr. Joaquim - O bilhete vinha sempre pedindo alguma coisa de alimentação ou um detergente, uma bolacha, um café. Agora quando era uma coisa assim como um cigarro, bebida [...]. Outro dia mesmo o José chegou aqui, isso aí já foi um recado. Ai José chegou: 'Ô Sr. Joaquim tem foguete?' Eu falei: tem. Ele falou: 'Oh, vô falou pra você mandar uma caixa de doze tiros pra ele'. Eu fiquei assim né... ((gesto de pensativo)) E falei: oh, menino fala com ele que eu não mando não. Fala com ele que ele mesmo vem buscar. Ele falou: 'Não moço ele falou pra você mandar'. Eu falei: não, eu não mando não. Aí depois o avô não veio. Outro dia o avô dele apareceu aqui, então eu perguntei: você pediu José pra pegar uma caixa de foguete de doze tiros aqui? Ele disse: 'não'. Olha se eu mando, se eu confio e mando. Ainda mais Dona Jacqueline com esse negócio do conselho.

Pesquisadora - Conselho tutelar?

Sr. Joaquim - É. Eles chegou aqui e me mostrou o livro e explicou. Eu falei que não vendo pras crianças não. Eles trouxeram um livro grosso assim e eu assinei. ((indica a grossura do livro com os dedos))

Pesquisadora - Esse livro tinha o quê?

Sr. Joaquim - É assim pela parte de autoridade, de conselho. Eles deixaram também esse cartaz aqui oh ((mostrando o cartaz na parede)). Então, tudo isso é bom porque a gente se concentra mais e pega mais experiência. Eles vieram pra me informar e eu assinei como ciente. Tem muita criança que chega até com o dinheiro, mas eu digo: não senhor! Olha ali! ((apontando para o cartaz)) É justamente pra poder prestar atenção. Mesmo antes disso eu já não vendia pra as crianças. A gente pensa muito, pensa em como a gente foi criado e como a gente cria os da gente. Então é o caso que a gente também não vai querer o mal pros filhos dos outros. (Senhor Joaquim, entrevista, 2012).

Na transcrição supracitada podemos perceber a relevância da distinção feita pelo Sr. Joaquim entre bilhete e recado. Segundo Sr. Joaquim, a necessidade dessa solicitação foi reafirmada com a visita do Conselho Tutelar.

A visita do conselho tutelar à mercearia propiciou ao Sr. Joaquim o acesso a um livro que faz parte do domínio discursivo jurídico como ele descreveu: “É assim pela parte de autoridade, de conselho". Após a leitura das legislações que implicavam sanções para pontos comerciais que vendiam bebida, cigarro e outros produtos proibidos para menores, o Sr. Joaquim assinou o documento de que estava ciente das informações. O Sr. 
Joaquim, como seus fregueses que, ao assinarem os bilhetes, comprometiam-se a pagar o devido, firmou sua assinatura e comprometeu-se a cumprir a lei. Assim, o Sr. Joaquim precisava se resguardar do risco de as crianças usarem um suposto recado para comprar produtos não autorizados pelos adultos, e o bilhete com assinatura era exigido como forma de garantir a veracidade do pedido e ficar atento para, mesmo diante de um bilhete assinado por um adulto, não entregar produtos proibidos para um menor de idade. Nos eventos de letramento com a mercearia do Sr. Joaquim identificamos "situações demandantes" da escrita (KALMAM, 2004).

Essa experiência trouxe uma indagação ao Sr Joaquim. A princípio, foi algo diferente do combinado ser "recado" e não "bilhete". Depois, porque ele sabia que ainda que fosse bilhete, ele se responsabilizaria por qualquer acidente diante da lei, mesmo que a assinatura do avô indicasse a responsabilidade deste. O cartaz que o Sr. Joaquim recebeu do Conselho Tutelar foi afixado na parede da mercearia.

Observamos ainda no discurso do Sr. Joaquim um princípio incorporado na forma como foi educado, quanto a valores a serem transmitidos às novas gerações: "Mesmo antes disso eu já não vendia para as crianças. A gente pensa muito, pensa em como a gente foi criado e como a gente cria os da gente. Então é o caso que a gente também não vai querer o mal para os filhos dos outros".

Durante a conversa, o Sr. Joaquim mencionou que teve prejuízos na venda a prazo e, por isso, adotaria a "nota promissória" como forma de garantir o recebimento do valor dos produtos. Para o Sr. Joaquim, a nota promissória era o meio mais "seguro". Este seria outro gênero textual que seria utilizado pelo Sr. Joaquim que envolveria a escrita do valor da compra e a assinatura, que dariam garantias nas transações comerciais (relações de poder).

\section{Considerações}

Conclui-se que a escrita em espaços sociais da comunidade abrangia registros de fatos e relações sociais. A escrita está no posto de saúde, no posto telefônico e na mercearia. Textos como os cartazes e placas estavam disponíveis e eram direcionados a toda a comunidade.

Verificamos que a disponibilidade e o acesso à escrita se encontram em muitos espaços da comunidade. Os textos mais utilizados são aqueles que, de uma forma ou de 
outra, ordenam a prática social dos moradores (BARTON e HAMILTON, 1998). Como exemplo, podemos citar uma lista que relaciona os gêneros alimentícios de compras feitas na mercearia, o controle da distribuição de leite no posto de saúde e dados sobre a saúde dos moradores. Um cartaz serve de convite para uma festa de aniversário, para um evento na escola e para campanhas de prevenção de doenças. Bilhetes intermedeiam as compras de produtos na mercearia, mas também servem para levar e trazer recados dos pais e outros moradores. Uma tabela relaciona as ligações telefônicas e as visitas da agente de saúde.

Os textos mais valorizados são aqueles que, de algum modo, organizam o cotidiano das pessoas na comunidade. Esses textos abrangiam registros de fatos e relacionamentos da vida local. Resumindo a presença da escrita na comunidade, encontrase:

$\checkmark$ Escrita em locais públicos: placas de descentralização de recursos públicos nas ruas e em frente às instituições sociais (por exemplo, na casa de farinha e no posto de saúde); anúncios e cartazes no posto de saúde, escola, igreja, mercearia, casasbar e no período das eleições municipais outdoor, "santinhos" e folders dos candidatos foram espalhados pela comunidade.

$\checkmark$ Escrita em suportes de leitura: Bíblia, livros de histórias infantis e de adultos, documentos pessoais e da aposentadoria, contas de luz e boletos de contribuições para a igreja do Divino pai eterno e outros boletos bancários, revistas, jornais, revistas de propagandas de produtos, embalagens de produtos, CD, DVD, calendários, livros didáticos, revistas de receitas, mensagens bíblicas e outros.

$\checkmark$ Escrita em suportes de registro: cadernos de atas, fichas, folhas avulsas, agendas, celulares, computador, cadernos de receitas, cadernos escolares.

Entretanto, quanto aos conflitos entre moradores, relativos a nascimentos, casamentos, falecimentos, não havia registros disponíveis na comunidade (esses registros estavam sob os cuidados de instituições na cidade. Contudo, os moradores tinham acesso a certidões de nascimento, casamento ou óbito, identidade, CPF, título de eleitor e cartões de banco etc.).

No posto telefônico, a interação na utilização dos serviços era intermediada pelo registro de controle das ligações feitas no caderno através de uma tabela. Um adolescente poderia assumir a tarefa na ausência da responsável pelo serviço, e essa flexibilidade era 
reconhecida pelos moradores. $O$ bilhete, gênero textual de maior circulação na comunidade, era um instrumento importante nas negociações comerciais entre o dono da mercearia e os clientes.

Em todas essas circunstâncias de evento de letramento - atendimento da agente de saúde, utilização do telefone, compra de produtos na mercearia - um padrão que surgiu foi a assinatura como forma de acordar o serviço. No entanto, existe uma diferença entre o serviço da agente de saúde, o serviço telefônico e o da mercearia. O serviço da agente de saúde precisa da assinatura do paciente como forma de confirmar o cumprimento de sua atribuição. Já a assinatura nos casos do posto telefônico e da mercearia, a escrita tinha uma importância fundamental, pois o comprador assumia a responsabilidade civil por seus atos, isto é, relações pessoais, sociais e de consumo que implicavam deveres morais. Percebemos nesses casos relações de poder permeadas pela escrita.

Os fatos evidenciados até aqui revelam a disponibilidade e o acesso à escrita pelas crianças colaboradoras deste estudo. Em contrapartida, apesar da riqueza dessa interação com a escrita na comunidade, a escola inserida nesse espaço não percebia esses saberes como fundos de conhecimentos que poderiam ser integrados aos conteúdos escolares.

\section{Agradecimentos}

Agradecemos à Fundação de Amparo à Pesquisa do Estado de Minas Gerais (FAPEMIG) pelo apoio financeiro à pesquisa; em especial, as crianças colaboradoras da pesquisa e a comunidade de Jacarandá.

\section{REFERÊNCIAS}

BARTON, David; HAMILTON, Mary. Local Literacies. New York: Routledge, 1998.

HEATH, Shirley Brice. Ways with words: language, life, and work in communities and classrooms. New York: Cambridge University Press, 1983.

KALMAN, Judith. El acceso a la cultura escrita: la participación social y la apropiación de conocimientos en eventos cotidianos de lectura y escritura. Revista Mexicana de Investigación Educativa, México, Consejo Mexicano de Investigación Educativa, v. VIII, n. 17, enero-abril 2003, p. 37-66.

KALMAN, Judith. Saber lo que es la letra: una experiencia de lectoescritura con mujeres de Mixquic. 1 ed. México: Instituto de la Educación de la UNESCO, 2004. (Biblioteca para la actualización del maestro). 
MOLL, Luis C. Literacy research in community and classrooms: a sociocultural approach. In: BEACH, Richard.; GREEN, Judith.; KAMIL, Michael.; SHANAHAN, Timothy. (Eds.). Multiple disciplinary perspectives on literacy research. Urbana, IL: NCRE; NCTE, 1992. p. 211-240.

STREET, Brian Vincent. Literacy in theory and practice. Cambridge University Press, 1984.

STREET, Brian Vincent. Letramentos sociais: abordagens críticas do letramento no desenvolvimento, na etnografia e na educação. Trad. Marcos Bagno. São Paulo: Parábola Editorial, 2014. 